\title{
SOLVING MULTI-OBJECTIVE SUPPLIER SELECTION AND QUOTA ALLOCATION PROBLEM UNDER DISRUPTION USING A SCENARIO-BASED APPROACH
}

\author{
Farnaz Javadi Gargari, Mehdi Seifbarghy*
}

Industrial Engineering Department, Alzahra University, Deh Vanak, Tehran, Iran

\begin{tabular}{l}
\hline ARTICLE INFO \\
\hline Article history: \\
Received: 15.8 .2018$. \\
Received in revised form: 22.10 .2018$. \\
Accepted: 22.10 .2018$. \\
\hline Keywords: \\
Disruption \\
Supplier Selection \\
Scenario-based Method, \\
Supply Chain Management, \\
Quota Allocation \\
\hline DOI: http://doi.org/10.30765/er.40.3.08
\end{tabular}

\section{Introduction}

Supply chain is a complex logistics system in which raw materials are converted into the final product and are delivered to final consumers [1]. A supply chain management has three main processes including [2]:

\begin{abstract}
:
Nowadays, experts believe there are abundant sources of risks in a supply chain. An important group of risks against a supply chain is the disruption risks group, which disturbs the flow of material in the chain and may lead to inefficiency in providing the final product in the supply chain. The aim of this article is to investigate the control of costs of disruption in a supply chain by considering the possibility of disruption. In fact, this research focuses on determining the best combination of suppliers and quota allocation with regards to disruption in suppliers. The proposed multi-objective mathematical model in this paper is a mixed-integer programming (MIP) model with objective functions to minimize transaction costs of suppliers, expected costs of purchasing goods, expected percentages of delayed products, expected returned products, and to maximize expected evaluation scores of the selected suppliers. Due to the uncertainty of demand and supplier disruption in the real world, their values are also considered uncertain; the proposed multi-objective model is studied by using a scenario-based stochastic programming (SP) method. In this method, all possible predictions for demand and disruption values are simultaneously included in the model; objective function results have more optimal value than a separate solution of the model for each predicted value.
\end{abstract}

1 Information Management:

Nowadays, the role and importance of information is evident to everyone. Proper circulation and transfer of information plays an important role in making processes more efficient, effective, and easier to manage. Coordination in activities is very important in a supply chain. Coordinated and appropriate

\footnotetext{
* Corresponding author. Tel.: +98 (0) 9121232308

E-mail address: m.seifbarghy@alzahra.ac.ir
} 
information management among partners have incremental effect on decisions, speed, accuracy, quality, and other aspects.

2 Logistics Management:

This role covers all the physical activities from the procurement of raw materials to the final product including transportation activities, warehousing, production schedules, and etc.

3 Relationship Management:

This is one of the most important supply chain issues and has a significant impact on all fields in a supply chain and its performance level. Many initial failures in a supply chain are due to poor communication of expectations and behaviors that occur between various parties involved in the chain; trust and reliability among the parties is a critical and important element of success.

Delays in preparation of orders after a scheduled delivery period are inevitable in the production system. These delays impose costs on the system including loss of reputation among customers, destruction of goods or raw materials in food production systems, and increasing costs. Outsourcing in the supply chain followed by correct supplier selection has been used as a solution to reduce costs and increase flexibility [3]. Nowadays, companies are increasingly outsourcing their businesses including IT infrastructure, purchase of raw materials, after-sales services, logistics, and transportation. In fact, outsourcing executive-level processes (like transportation and warehousing) is related to basic outsourcing; outsourcing programming and decision-making levels (like distribution and network management) is concerned with the advanced outsourcing [4].

Generally, supplier selection is one of the most important and critical decisions which is not only responsible for the supply of components but also for maintaining an organization in a competitive environment. Supplier selection becomes even more important when an organization needs to choose a supplier for more than one particular period at a different cost, delivery time, and delay [5]. On one hand, examples of these trends include globalization of commerce, outsourcing of internal functions, and reduction of the level of reserve in a chain with the help of a timely production philosophy; on the other hand, business environments today are dealing with uncertain factors more than ever, and even the most efficient systems are not immune to risk, disruption, or damage. In other words, disruption is one of the most important issues with regard to the global supply chain, which can quickly be disseminated to other parts.

Supply chain disruption management is a structured and continuous process to analyze the impact of disruptions on predetermined goals and to manage disruptions throughout its life cycle in a supply chain. In some disruptions, the greatest attention should be paid to prevent disruption; while for others, the focus needs to be on reducing its effects after the disruption occurs [6].

In the next section, a brief summary of the studies conducted in the field is given.

\section{Literature review}

Karpak et al. [7] provided an ideal programming model for evaluating and selecting a supplier with three objectives of cost, quality, and delivery capability. Amid et al. [8] proposed a fuzzy multiobjective linear programming model. This model considered the ambiguity and inaccuracy of input data, and helped decision-makers to supply the optimum quantity of order for each supplier. Their model had three objective functions with different weights. Objective functions included minimizing prices and maximizing quality and services; and constraints included demand and capacity. Lee and Chang [9] proposed a supplier selection model with four objective functions to minimize costs, returns, and delays in delivery, and maximize supplier flexibility, in which the demand was stochastic and the genetic algorithm used for solving this problem. Razmi and Maghol [10] suggested a fuzzy twodisciplinary model under a multi-period programming horizon for procurement and supplier selection problems in which budget and capacity were the problem constraints. This model included a variety of discount policies (generalized and partial) with different payment methods suggested by each supplier. Li and Zabinsky [11] proposed a two-stage probabilistic approach to determine the minimum number of suppliers and the allocation of each share taking discounts into account. This approach included the stochastic programming (SP) model and chance constrained programming (CCP); both models had several objective functions. The first objective function was to minimize the number of suppliers, and the second was to minimize the total expected cost and order allocation to each supplier. Mafakheri et al. [12] proposed a two-step method for multi-criteria dynamic programming to determine supplier and order allocation. In the first stage, the analytical hierarchy process (AHP) was used for 
ranking of suppliers; and in the second stage of assignment, an order was allocated to each supplier in a way that utility function was maximized and supply chain costs were minimized. Ozkok and Tiryaki [13] proposed a compensatory fuzzy model to solve the multi-objective linear selection problem using the Werner technique. Kamali et al. [14] proposed a multi-objective linear mixed integer programming (MIP) model for systems with buyers and multi-supplier under the general discount policy, using two metaheuristic algorithms due to the complexity. Mendoza and Ventura [15] used two nonlinear MIP models to select the best set of suppliers and assign the order value to each supplier. In the proposed models, the goal was to minimize the annual order quantity and keep inventory and purchase costs under the quality and capacity constraints of the supplier. Sepúlveda and Ivan [16] provided automated performance reasoning for the assessment of supplier performance in a supply chain and used the fuzzy process for supplier ranking. They considered three criteria including economy, service, and quality. Maden et al. [17] argued that in order to increase their competitive ability, organizations should standardize and improve their processes for supplying products with better quality and lower costs. They proposed a model with two goals of minimization of costs and maximization of efficiency. Pellegrino et al. [18] addressed the supply chain financing challenge by adopting the supply chain perspective and analyzed it with the effectiveness of supply chain risk management (SCRM) strategies. Hsieh and Chiu [19] attempted to improve the match between quality specifications (QS) and components of a supply chain. Zair et al [20] proposed a model based on the multi-objective optimization approach in which the costs of resources collaboration, the risks of this collaboration and quality of delivered services were examined.

One of the issues which has not been addressed in the background research in this area is to consider supplier disruptions as one of the real-world realities. Supply chains are inherently dealing with risk. They pass raw materials and products from different paths and, in this way, work with different operations, goals, cultures, and structures so that they are able to distribute products all over the world. These risks to supply chains come from the external environment; for example, from earthquakes, storms, wars, terrorist attacks, disease outbreaks, rising prices, problems with partners, crime, technological changes, financial irregularities, changing rules and regulations, etc. [21]. Although the likelihood of a disruption is very low, recent events suggest that ignoring this issue during the design of a supply chain can cause irreparable damages. The dynamic and inaccurate nature of the quantity and quality of manufactured products has created a high degree of uncertainty and risk in supply chains; therefore, identifying these risks is of great importance [22]. Additionally, coordination in a supply chain can improve its performance (including those of manufacturers, suppliers of logistics, and independent retailers) and control its disruption [23]. Supplier selection and optimal quota allocation affects many conditions including the number of needed products and items, the number of selected suppliers for each product, the number of decision cycles, and the capacity of each supplier. Along with the conditions stated for choosing a supplier, the likelihood of disruption for real-world suppliers has made optimal decisionmaking more difficult for managers. In fact, addressing supplier disruption can reduce and control costs of supply chain risks.

In this paper, a mixed-integer programming (MIP) model under disruption is presented to determine quota allocation to each supplier; two types of supplier are considered in the model. Reliable suppliers and unreliable suppliers; reliable suppliers do not come across disruption in the operating period or they undertake all costs of probable disruptions while unreliable suppliers may come across disruption and may transfer the costs of disruptions to the buyer company. Considering the unstable world and needing to future studies in supply chain management, scenario-based stochastic programming method has been used to model the problem and tackle the uncertainties.

In the following section of this paper, notations are given and the problem is formulated. In Section 4, solution methods considering the stochastic version of the model are given. Then, in Section 5, numerical results and sensitivity analysis of the solution method are provided. Finally, a summary of the results and further research ideas are given in Section 6.

\section{Notation and problem formulation}

This paper presents a multi-objective model for supplier selection and for determining the optimal quota allocation to each supplier with regards to disruption of suppliers. Objective functions of the proposed model include minimizing transactions costs with suppliers and minimizing expected purchasing costs from suppliers, and minimizing expected percentages of delayed goods and returned 
goods and finally maximizing the expected scores of suppliers [24]. Generally, two types of suppliers are defined with regards to the problem reliable suppliers and unreliable suppliers. If the buyer allocates a quota to a reliable supplier, he will 100 percent receive the quota; but if the buyer allocates a quota to an unreliable supplier, the addressed supplier may not meet the quota because of disruption. In this case a backup supplier will satisfy the quota. The existence of backup suppliers for unreliable suppliers ensures buyer's quota to be met, however, there will be costs of disruption for the buyer-suppliers supply chain. Here, notations are given in Table 1 and the mathematical model is given as in Equations (1) to (19). Assumptions of the problem are as follows:
- Suppliers may be non-accessible because of disruption

- Delay in providing each quota is allowed

- Returning product to suppliers by customers is allowed

- The problem is investigated in multiple periods

- Each quota can be allocated to either reliable suppliers or unreliable suppliers which are supported by reliable backup suppliers

- There is no limitation in the number of selected backup suppliers

- Reliable suppliers do not need to be supported by backup suppliers

\section{Table 1. Notations}

\begin{tabular}{|c|c|}
\hline$i$ : Reliable supplier index & $j:$ Product index \\
\hline$k$ : Unreliable supplier index & $t$ : Time period index \\
\hline \multicolumn{2}{|l|}{ Parameters } \\
\hline$D_{j t}:$ Demand of product $j$ at period $t$ & $\begin{array}{l}C_{i j t} \text { : Capacity of reliable supplier } i \text { for supplying product } \\
j \text { at period } t\end{array}$ \\
\hline$R_{k}$ : Probability of disruption in unreliable supplier $k$ & $\begin{array}{l}C C_{k j t} \text { : Capacity of unreliable supplier } k \text { for supplying } \\
\text { product } j \text { at period } t\end{array}$ \\
\hline $\begin{array}{l}P_{i j t}: \text { Unit price of product } j \text { given by reliable supplier } i \text { at } \\
\text { period } t\end{array}$ & $\begin{array}{l}a_{i j} \text { : Transaction costs of providing product } j \text { via reliable } \\
\text { supplier } i\end{array}$ \\
\hline $\begin{array}{l}P P_{k j t}: \text { Unit price of product } j \text { given by unreliable supplier } \\
k \text { at period } t\end{array}$ & $\begin{array}{l}a a_{k j} \text { : Transaction costs of providing product } j \text { via } \\
\text { unreliable supplier } k\end{array}$ \\
\hline $\begin{array}{l}w_{i}: \text { Score of reliable Supplier } i \text { based on periodical } \\
\text { evaluation }\end{array}$ & $\begin{array}{l}\alpha_{i j t}: \text { Binary parameter (equal to one if product } j \text { can be } \\
\text { supplied by reliable supplier } i \text { at period } t \text {; otherwise, zero) }\end{array}$ \\
\hline $\begin{array}{l}w w_{k}: \text { Score of unreliable Supplier } k \text { based on periodical } \\
\text { evaluation }\end{array}$ & $\begin{array}{l}\alpha \alpha_{k j t} \text { : Binary parameter (equal to one if product } j \text { can be } \\
\text { supplied by unreliable supplier } k \text { at period } t \text {; otherwise, } \\
\text { zero) }\end{array}$ \\
\hline$\underset{j}{Q j: \text { Maximum acceptable percentage of returned product }}$ & $\begin{array}{l}T_{j} \text { : Maximum acceptable percentage of delays of product } \\
j\end{array}$ \\
\hline$q_{i j}:$ Percentage of returned product $j$ to reliable supplier $i$ & $\begin{array}{l}t_{i j} \text { : Percentage of late delivered product } j \text { by reliable } \\
\text { supplier } i\end{array}$ \\
\hline $\begin{array}{l}q q_{k j}: \text { Percentage of returned product } j \text { to unreliable } \\
\text { supplier } k\end{array}$ & $\begin{array}{l}t t_{k j}: \text { Percentage of late delivered product } j \text { by unreliable } \\
\text { supplier } k\end{array}$ \\
\hline \multicolumn{2}{|l|}{ Variables } \\
\hline $\begin{array}{l}X_{i j t} \text { : Binary variable of selecting reliable supplier } i \text { for } \\
\text { supplying product } j \text { at period } t\end{array}$ & $\begin{array}{l}X X_{k j t} \text { : Binary variable of selecting unreliable supplier } k \text { for } \\
\text { supplying product } j \text { at period } t\end{array}$ \\
\hline $\begin{array}{l}Y_{i j t}: \text { Percentage of demand of product } j \text { met by reliable } \\
\text { supplier } i \text { at period } t \text { as the main supplier }\end{array}$ & $\begin{array}{l}Y P_{k j t}: \text { Percentage of demand of product } j \text { met by unreliable } \\
\text { supplier } k \text { at period } t \text { as the main supplier }\end{array}$ \\
\hline $\begin{array}{l}Y B_{i k j t}: \text { Percentage of demand of product } j \text { met by reliable } \\
\text { supplier } i \text { at period } t \text { as the backup of unreliable supplier } k\end{array}$ & \\
\hline
\end{tabular}

$\operatorname{Min} Z_{1}: \sum_{i} \sum_{k} \sum_{j} \sum_{t}\left(a_{i j} X_{i j t}+a a_{K j} X X_{K j t}\right)$

Min $\left.Z_{2}: \sum_{i} \sum_{k} \sum_{j} \sum_{t}\left(p_{i j t}\left(Y_{i j t}+Y B_{i k j t}\left(R_{k}\right)\right)+p p_{k j t} Y P_{k j t}\left(1-R_{k}\right)\right)\right) D_{j t}$

$\left.\operatorname{Min} Z_{3}: \sum_{i} \sum_{k} \sum_{j} \sum_{t}\left(q_{i j}\left(Y_{i j t}+Y B_{i k j t}\left(R_{k}\right)\right)+q q_{k j} Y P_{k j t}\left(1-R_{k}\right)\right)\right) D_{j t}$

$\left.\operatorname{Min} Z_{4}: \sum_{i} \sum_{k} \sum_{j} \sum_{t}\left(t_{i j}\left(Y_{i j t}+Y B_{i k j t}\left(R_{k}\right)\right)+t t_{k j} Y P_{k j t}\left(1-R_{k}\right)\right)\right) D_{j t}$

$\left.\operatorname{Max} Z_{5}: \sum_{i} \sum_{k} \sum_{j} \sum_{t}\left(w_{i}\left(Y_{i j t}+Y B_{i k j t}\left(R_{k}\right)\right)+w w_{k} Y P_{k j t}\left(1-R_{k}\right)\right)\right) D_{j t}$ 
Eq. (1) gives the first objective function which minimizes the total transaction cost of products. The transaction cost includes those fixed costs of establishing relations and cooperation with suppliers such as supplier selection, negotiations for contracting, inspection of goods, quality control, etc. Eq. (2) gives the second objective function which minimizes the expected total purchasing costs paid by the buyer to suppliers. Eq. (3) gives the third objective function in which the expected total percentage of returned products are minimized. This cost occurs when the supplier is unable to supply the customer demand with expected quality. Eq. (4) gives the fourth objective function which minimizes the expected total percentage of late delivered products. Eq. (5) gives the fifth objective function which maximizes the expected scores of the selected suppliers based on a conducted periodical evaluation.

Model constraints are given as in Eq. (6) to (19).

$\sum_{i} \sum_{k}\left(Y_{i j t}+Y P_{k j t}\right)=1$

$\forall j, t$
$\forall k, j, t$
$\forall j$
$\forall j$
$\forall i, j, t$
$\forall k, j, t$
$\forall k, j, t$
$\forall i, k, j, t$
$\forall i, j, t$
$\forall i, j, t$
$\forall k, j, t$
$\forall i, k, j, t$
$\forall i, j, t$
$\forall k, j, t$

Constraint (6) refers to meeting the buyers demand for each product at each time period by the reliable or unreliable suppliers. Constraint (7) refers to equality of the percentage of satisfied demand by each unreliable suppliers and its backup suppliers. Constraint (8) guarantees that the total percentages of returned product for all periods and for each product do not exceed the maximum acceptable percentage of each product. Constraint (9) guarantees that the total percentages of late delivered product for all periods and for each products do not exceed the maximum acceptable percentage of each product. Constraints (10) and (11) control that the total products supplied by reliable and unreliable suppliers do not exceed their initial given capacities. Constraints (12), (13), and (14) controls that each supplier to be selected before to be allocated a quota. Constraints (15)-(19) indicate the given values of the decision variables of the model. Considering that there is not a unique optimum solution for multi-objective problems, adaptive optimal solutions are often considered tackling such problems. Multi-choice goal programming technique is a suitable approach to solve these problems. In the traditional goal

programming, exact determination of the values for the goals is obligatory; but the decision-maker does not always have complete and accurate information about the goals, and about the importance of each goal. In this situation, most decisions are based on inaccurate information and data; thus, by introducing the theory of fuzzy sets, uncertainty has entered into traditional decision-making problems. In this paper, fuzzy multichoice goal programming is used to solve the problem. In this solving method, three goals (choices) are considered for each objective function. The model selects a value among these three given choices for each function so that the solution of all objective functions to be close to their optimal solutions. In this paper, a linearized model of this method is presented for the ease and accuracy in solving the problem [25]. The new notations introduced in the model as well as the linearized model of the fuzzy three-choice goal programming method are in accordance with Table 2 and relationships (20) to (30), respectively. Furthermore, Constraints (6) to (19) should be added to the model. 
Table 2. The Fuzzy three-choice goal programming model

\begin{tabular}{lc}
\hline Parameters \\
$\begin{array}{l}\widetilde{g_{1}} \ldots \widetilde{g_{15}}: \text { Considered fuzzy goal values for the five } \\
\text { objective functions, respectively }\end{array}$ & $\begin{array}{l}\boldsymbol{d}_{\mathbf{1}}^{-} \ldots \boldsymbol{d}_{\mathbf{1 2}}^{-}: \text {Maximum negative permissible deviation of } \\
\text { each aspiration choice of the relevant objective function } \\
\text { value }\end{array}$ \\
\hline $\begin{array}{l}f_{1} \ldots f_{5}: \text { The weights of the five objective functions, } \\
\text { respectively }\end{array}$ & $\begin{array}{c}\boldsymbol{d}_{13}^{+} \ldots \boldsymbol{d}_{15}^{+}: \text {Maximum positive permissible deviation } \\
\text { of each aspiration choice of the relevant objective } \\
\text { function value }\end{array}$ \\
\hline Variables & $\begin{array}{l}\mu_{1} \ldots \mu_{\mathbf{5}}: \text { The membership function values of the five } \\
\text { objective functions, respectively }\end{array}$ \\
\hline $\begin{array}{l}v_{1} \ldots v_{10}: \text { Binary variable of aspiration choice } \\
u_{1} \ldots u_{5}: \text { Continuous variables of aspiration choice }\end{array}$
\end{tabular}

$\operatorname{Max} z t=f_{1} \mu_{1}+f_{2} \mu_{2}+f_{3} \mu_{3}+f_{4} \mu_{4}+f_{5} \mu_{5}$

Eq. (20) refers to maximizing the membership function of each single objective function.

$$
\begin{aligned}
& \mu_{1} \leq 1-\left(\frac{z_{1}-\widetilde{g_{1}}}{d_{1}^{-}} u_{1}+\frac{z_{1}-\widetilde{g_{2}}}{d_{2}^{-}}\left(v_{1}-u_{1}\right)+\frac{z_{1}-\widetilde{g_{3}}}{d_{3}^{-}}\left(v_{2}-u_{1}\right)\right. \\
& \mu_{2} \leq 1-\left(\frac{z_{2}-\widetilde{g_{4}}}{d_{4}^{-}} u_{2}+\frac{z_{2}-\widetilde{g_{5}}}{d_{5}^{-}}\left(v_{3}-u_{2}\right)+\frac{z_{2}-\widetilde{g_{6}}}{d_{6}^{-}}\left(v_{4}-u_{2}\right)\right. \\
& \mu_{3} \leq 1-\left(\frac{z_{3}-\widetilde{g_{7}}}{d_{7}^{-}} u_{3}+\frac{z_{3}-\widetilde{g_{8}}}{d_{7}^{-}}\left(v_{5}-u_{3}\right)+\frac{z_{3}-\widetilde{g_{9}}}{d_{9}^{-}}\left(v_{6}-u_{3}\right)\right. \\
& \mu_{4} \leq 1-\left(\frac{z_{4}-\widetilde{g_{10}}}{d_{10}^{-}} u_{4}+\frac{z_{4}-\widetilde{g_{11}}}{d_{11}^{-}}\left(v_{7}-u_{4}\right)+\frac{z_{4}-\widetilde{g_{12}}}{d_{12}^{-}}\left(v_{8}-u_{4}\right)\right. \\
& \mu_{5} \leq 1-\left(\frac{\widetilde{g_{13}}-z_{5}}{d_{13}^{+}} u_{5}+\frac{\widetilde{g_{14}}-z_{5}}{d_{14}^{+}}\left(v_{9}-u_{5}\right)+\frac{\widetilde{g_{15}}-z_{5}}{d_{15}^{+}}\left(v_{10}-u_{5}\right)\right. \\
& u_{1} \leq\left\{\begin{array}{l}
v_{1} \\
v_{2}
\end{array}, u_{2} \leq\left\{\begin{array}{l}
v_{3} \\
v_{4}
\end{array}, u_{3} \leq\left\{\begin{array}{l}
v_{5} \\
v_{6}
\end{array}, u_{4} \leq\left\{\begin{array}{l}
v_{7} \\
v_{8}
\end{array}, u_{5} \leq\left\{\begin{array}{l}
v_{9} \\
v_{10}
\end{array}\right.\right.\right.\right.\right. \\
& u_{1} \geq v_{1}+v_{2}-1, u_{2} \geq v_{3}+v_{4}-1, u_{3} \geq v_{5}+v_{6}-1, u_{4} \geq v_{7}+v_{8}-1, u_{5} \geq v_{9}+v_{10}-1 \\
& u_{1} \ldots u_{5} \geq 0 \\
& v_{1} \ldots v_{10} \in\{0,1\} \\
& \mu_{1} . . \mu_{5} \geq 0
\end{aligned}
$$

Subject to Eq. (6)-(19)

Relations (21) to (25) relate to controlling the membership function values of $Z_{1}$ to $Z_{5}$ which are due to minimizing $Z_{1}$ to $Z_{5}$; the maximum negative permissible deviation of each aspiration choice of the relevant objective function value are considered for the first four objective function because of minimizing their own values. At the same time, the maximum value of the positive deviation of aspiration choice of the relevant objective function value is considered for the fifth objective function because of maximizing its own value. Relationship (26) deals with the limitation of choosing the aspiration, which shows that in each function the model is allowed to select an aspiration. Relations (27) are the relations between the binary and continuous variables of the fuzzy goal programming method. Relationship (28) deals with the linearization of the model. Relationships (29) and (30) represent the type and range of variables.

\section{Solution methods}

In this paper, an extensive SP approach is used to solve the problem. SP belongs to the more general category of uncertainty programming, which includes dynamic programming, decision trees, simulations, stochastic processes, and possible constraints. In the scenario-based programming method, stochastic quantities are considered to be stochastic variables. A scenario is an assumption about the future, which expresses the interaction between different factors under certain conditions. In fact, scenarios are a combination of stochastic parameters and a summary of different data modes in a few simple ways. Naturally, scenarios are created based on possible modes of the parameters. To model the problem, parameters with likelihood of uncertainties in the real world are considered to be 
uncertain. Obviously, in the real world, unstable domestic and foreign economic conditions, foreign exchange market volatility, security situation, and etc., lead to volatile demand. Additionally, disasters like earthquakes, storms, fires, strikes by employees, etc. cause variability in the amount of supplier disruptions. In this paper, we considers two

Table 3 . The symbols of the scenario-based model parameters of demand and disruption probability under different scenarios.

Table 3 illustrates the definition of notations under scenario-based planning. It should be noted that only some variables are affected by scenario-based planning.

\begin{tabular}{l}
\hline$i$ : Reliable supplier index \\
\hline$k$ : Unreliable supplier index \\
\hline$S_{l}:$ Scenario index for demand \\
\hline$e:$ The index of the combination of scenarios of demand \\
and the disruption probabilities of unreliable suppliers \\
\hline parameters \\
\hline $\boldsymbol{D}_{\boldsymbol{j} \boldsymbol{t}}^{\boldsymbol{s}_{\mathbf{1}}}:$ Demand of product $j$ at period $t$ under Scenario $S_{l}$ \\
\hline $\boldsymbol{R}_{\boldsymbol{k}}^{\boldsymbol{s}_{\mathbf{2}}}:$ Disruption probability of unreliable supplier $k$ under \\
Scenario $\mathrm{S}_{2}$ \\
\hline$P_{i j t}:$ Unit price of product $j$ given by reliable supplier $i$ at \\
period $t$ \\
\hline$P P_{k j t}$ : Unit price of product $j$ given by unreliable supplier $k$ \\
at period $t$ \\
\hline$w_{i}:$ Score of reliable Supplier $i$ based on periodical \\
evaluation \\
\hline$w w_{k}:$ Score of unreliable Supplier $k$ based on periodical \\
evaluation
\end{tabular}

$Q j$ : Maximum acceptable percentage of returned product $j$ $q_{i j}$ : Percentage of returned product $j$ to reliable supplier $i$ $q q_{k j}$. Percentage of returned product $j$ to unreliable supplier $k$ $j$ : Product index $t$ : Time period index $S_{2}$ : Scenario index for disruption probabilities of unreliable suppliers

$C_{i j t}$ : Capacity of reliable supplier $i$ for supplying product $j$ at period $t$

$C C_{k j t}$ : Capacity of unreliable supplier $k$ for supplying product $j$ at period $t$

$a_{i j}$ : Transaction costs of providing product $j$ via reliable supplier $i$

$a a_{k j}$ : Transaction costs of providing product $j$ via unreliable supplier $k$

$\alpha_{i j t}$ : Binary parameter (equal to one if product $j$ can be supplied by reliable supplier $i$ at period $t$; otherwise, zero)

$\alpha \alpha_{k j t}$ : Binary parameter (equal to one if product $j$ can be supplied by unreliable supplier $k$ at period $t$; otherwise, zero)

$T_{j}$ : Maximum acceptable percentage of delays of product $j$ $t_{i j}$ : Percentage of late delivered product $j$ by reliable supplier $i$

$t t_{k j}$ : Percentage of late delivered product $j$ by unreliable supplier $k$

$X X_{k j t}$ : Binary variable of selecting unreliable supplier $k$ for supplying product $j$ at period $t$

$Y P^{e}{ }_{k j t}$ : Percentage of demand of product $j$ met by unreliable supplier $k$ at period $t$ as the main supplier under scenario e

$Y B^{e}{ }_{i k j t}$ Percentage of demand of product $j$ met by reliable supplier $i$ at period $t$ as the backup of unreliable supplier under scenario e

$\operatorname{Min} Z_{1}: \sum_{i} \sum_{k} \sum_{j} \sum_{t}\left(a_{i j} X_{i j t}+a a_{k j} X X_{k j t}\right)$

Min $\left.Z_{2}^{e}: \sum_{i} \sum_{k} \sum_{j} \sum_{t}\left(p_{i j t}\left(Y_{i j t}^{e}+Y B_{i k j t}^{e}\left(R_{k}^{S_{2}}\right)\right)+p p_{k j t} Y P_{k j t}^{e}\left(1-R_{k}^{S_{2}}\right)\right)\right) D_{j t}^{S_{1}} \quad \forall e$

Min $\left.Z_{3}^{e}: \sum_{i} \sum_{k} \sum_{j} \sum_{t}\left(q_{i j}\left(Y_{i j t}^{e}+Y B_{i k j t}^{e}\left(R_{k}^{S_{2}}\right)\right)+q q_{k j} Y P_{k j t}^{e}\left(1-R_{k}^{S_{2}}\right)\right)\right) D_{j t}^{S_{1}} \quad \forall e$

Min $\left.Z_{4}^{e}: \sum_{i} \sum_{k} \sum_{j} \sum_{t}\left(t_{i j}\left(Y_{i j t}^{e}+Y B_{i k j t}^{e}\left(R_{k}^{s_{2}}\right)\right)+t t_{k j} Y P_{k j t}^{e}\left(1-R_{k}^{s_{2}}\right)\right)\right) D_{j t}^{s_{1}} \quad \forall e$

$\left.\operatorname{Max} Z_{5}^{e}: \sum_{i} \sum_{k} \sum_{j} \sum_{t}\left(w_{i}\left(Y_{i j t}^{e}+Y B_{i k j t}^{e}\left(R_{k}^{s_{2}}\right)\right)+w w_{k} Y P_{k j t}^{e}\left(1-R_{k}^{s_{2}}\right)\right)\right) D_{j t}^{s_{1}} \quad \forall e$

$\sum_{i} \sum_{k}\left(Y_{i j t}^{e}+Y P_{k j t}^{e}\right)=1$

$\forall j, t, e$

$Y P_{k j t}^{e}-\sum_{i} Y B_{i k j t}^{e}=0$ 


$$
\begin{array}{ll}
\sum_{i} \sum_{k} \sum_{t}\left(q_{i j}\left(Y_{i j t}^{e}+Y B_{i k j t}^{e}\left(R_{k}^{S_{2}}\right)\right)+q q_{k j} Y P_{k j t}^{e}\left(1-R_{k}^{S_{2}}\right)\right) \leq Q_{j} & \forall j, e \\
\sum_{i} \sum_{k} \sum_{t}\left(t_{i j}\left(Y_{i j t}^{e}+Y B_{i k j t}^{e}\left(R_{k}^{s_{2}}\right)\right)+t t_{k j} Y P_{k j t}^{e}\left(1-R_{k}^{s_{2}}\right)\right) \leq T_{j} & \forall j, e \\
\left(Y_{i j t}^{e}+\sum_{k}\left(R_{k}^{S_{2}}\right) Y B_{i k j t}^{e}\right) D_{j t}^{s_{1}} \leq C_{i j t} \alpha_{i j t} & \forall i, j, t, e \\
Y P_{k j t}^{e}\left(1-R_{k}^{S_{2}}\right) D_{j t}^{S_{1}} \leq C C_{k j t} \alpha \alpha_{k j t} & \forall k, j, t, e \\
Y P_{k j t}^{e} \leq X X_{k j t} & \forall j, t, k, e \\
Y B_{i k j t}^{e} \leq X_{i j t} & \forall i, j, k, t, \mathrm{e} \\
Y_{i j t}^{e} \leq X_{i j t} & \forall i, j, t, e \\
0 \leq Y_{i j t}^{e} \leq 1 & \forall i, j, t, \mathrm{e} \\
0 \leq Y P_{k j t}^{e} \leq 1 & \forall k, j, t, e \\
0 \leq Y B_{i k j t}^{e} \leq 1 & \forall i, k, j, t, e
\end{array}
$$

Explanation of all equations is similar to their corresponding equations from (1) to (19) with the

\begin{tabular}{|c|c|}
\hline \multicolumn{2}{|l|}{ Parameters } \\
\hline $\begin{array}{l}\widetilde{g_{1}} \ldots \widetilde{g_{3}}: \text { Considered three fuzzy goal values for the } \\
\text { first objective function }\end{array}$ & $\begin{array}{l}\boldsymbol{d}_{\mathbf{1}}^{-} \ldots \boldsymbol{d}_{\mathbf{3}}^{-} \text {: Maximum negative permissible deviation of } \\
\text { each aspiration choice of the first objective function } \\
\text { value }\end{array}$ \\
\hline $\begin{array}{l}\tilde{g}_{3}^{e} \ldots \tilde{g}_{15}^{e} \text { Considered fuzzy goal values for the objective } \\
\text { functions } 2,3,4 \text { and } 5 \text {, respectively }\end{array}$ & $\begin{array}{l}\boldsymbol{d}_{4}^{-e} \ldots \boldsymbol{d}_{12}^{-e}: \text { Maximum negative permissible deviation } \\
\text { of each aspiration choice of the second, third and fourth } \\
\text { objective function values in any combination }\end{array}$ \\
\hline $\begin{array}{l}\rho^{e}: \text { The probability of occurrence of any combination } \\
\text { mode of demand and disruption probability }\end{array}$ & $\begin{array}{l}\boldsymbol{d}_{13}^{+e} \ldots \boldsymbol{d}_{15}^{+e} \text { : Maximum positive permissible deviation } \\
\text { of each aspiration choice of the fifth objective function } \\
\text { value in any combination }\end{array}$ \\
\hline \multicolumn{2}{|l|}{ Variables } \\
\hline $\begin{array}{l}v_{1}, v_{2}, v_{3}^{e} \ldots v_{10}^{e}: \text { Binary Variable of aspiration choice } \\
\text { in any combination mode of demand and disruption } \\
\text { probability } \\
u_{1}, u_{2}^{e} . . u_{5}^{e} \text { : Continuous variables of aspiration choice } \\
\text { in any combination mode of demand and disruption } \\
\text { probability }\end{array}$ & $\begin{array}{l}\mu_{1}, \mu_{2}^{\mathrm{e}} \ldots \mu_{5}^{\mathrm{e}} \text { : The membership function values of the } \\
\text { five objective functions, respectively }\end{array}$ \\
\hline
\end{tabular}
difference being that the given model is based on the combination of scenarios of demand and disruption probabilities. As a result, four combined modes are obtained when both supplier disruption probabilities and demand values are considered. In general, a fuzzy multi-choice goal programming method is used along with the definitive model; the difference is that this model is repeated for all combinations and because there is no possibility of simultaneous occurrence of all combinations, the probability of occurrence of each combination of scenarios mode is considered in the model. Notations and the fuzzy three-choice goal programming model for extensive SP is given in Table 4. The corresponding mathematical model is given as in (48) to (58) considering (36)-(47) and (18)-(19).

Table 4. The Fuzzy three-choice goal programming model for making scenario

$\max z t: f_{1} \mu_{1}+\sum_{e} \rho^{e}\left(f_{2} \mu_{2}^{e}+f_{3} \mu_{3}^{e}+f_{4} \mu_{4}^{e}+f_{5} \mu_{5}^{e}\right)$

$\mu_{1} \leq 1-\left(\frac{z_{1}-\widetilde{g_{1}}}{\boldsymbol{d}_{1}^{-}} u_{1}+\frac{z_{1}-\widetilde{g_{2}}}{\boldsymbol{d}_{2}^{-}}\left(v_{1}-u_{1}\right)+\frac{z_{1}-\widetilde{g_{3}}}{\boldsymbol{d}_{3}^{-}}\left(v_{2}-u_{1}\right)\right.$

$\mu_{2}^{e} \leq 1-\left(\frac{z_{2}^{e}-\tilde{g}_{4}^{e}}{d_{4}^{-e}} u_{2}^{e}+\frac{z_{2}^{e}-\tilde{g}_{5}^{e}}{d_{5}^{-e}}\left(v_{3}^{e}-u_{2}^{e}\right)+\frac{z_{2}^{e}-\tilde{g}_{6}^{e}}{d_{6}^{-e}}\left(v_{4}^{e}-u_{2}^{e}\right)\right.$

$\mu_{3}^{e} \leq 1-\left(\frac{z_{3}^{e}-\tilde{g}_{7}^{e}}{d_{7}^{-e}} u_{3}^{e}+\frac{z_{3}^{e}-\tilde{g}_{8}^{e}}{d_{8}^{-e}}\left(v_{5}^{e}-u_{3}^{e}\right)+\frac{z_{3}^{e}-\tilde{g}_{9}^{e}}{d_{9}^{-e}}\left(v_{6}^{e}-u_{3}^{e}\right)\right.$ 


$$
\begin{aligned}
& \mu_{4}^{e} \leq 1-\left(\frac{z_{4}^{e}-\tilde{g}_{10}^{e}}{d_{10}^{-e}} u_{4}^{e}+\frac{z_{4}^{e}-\tilde{g}_{10}^{e}}{d_{10}^{-e}}\left(v_{7}^{e}-u_{4}^{e}\right)+\frac{z_{4}^{e}-\tilde{g}_{10}^{e}}{d_{10}^{-e}}\left(v_{8}^{e}-u_{4}^{e}\right) \quad \forall e\right. \\
& \mu_{5}^{e} \leq 1-\left(\frac{\tilde{g}_{13}^{e}-z_{5}^{e}}{d_{13}^{+e}} u_{5}^{e}+\frac{\tilde{g}_{13}^{e}-z_{5}^{e}}{d_{13}^{+e}}\left(v_{9}^{e}-u_{5}^{e}\right)+\frac{\tilde{g}_{13}^{e}-z_{5}^{e}}{d_{13}^{+e}}\left(v_{10}^{e}-u_{5}^{e}\right) \quad \forall e\right. \\
& u_{1} \leq\left\{\begin{array}{l}
v_{1} \\
v_{2}
\end{array}, u_{2}^{e} \leq\left\{\begin{array}{l}
v_{3}^{e} \\
v_{4}^{e}
\end{array}, u_{3}^{e} \leq\left\{\begin{array}{l}
v_{5}^{e} \\
v_{6}^{e}
\end{array}, u_{4}^{e} \leq\left\{\begin{array}{l}
v_{7}^{e} \\
v_{0}^{e}
\end{array}, u_{5}^{e} \leq\left\{\begin{array}{l}
v_{9}^{e} \\
v_{0}^{e}
\end{array} \quad \forall e\right.\right.\right.\right.\right. \\
& u_{1} \geq v_{1}+v_{2}-1, u_{2}^{e} \geq v_{3}^{e}+v_{4}^{e}-1, u_{3}^{e} \geq v_{5}^{e}+v_{6}^{e}-1, \quad \forall e \\
& u_{4}^{e} \geq v_{7}^{e}+v_{8}^{e}-1, u_{5}^{e} \geq v_{9}^{e}+v_{10}^{e}-1 \\
& u_{1}, u_{2}^{e} . . u_{5}^{e} \geq 0 \\
& v_{1}, v_{2}, v_{3}^{e} . . v_{10}^{e} \in\{0,1\} \\
& \mu_{1}, \mu_{2}^{e} . . \mu_{5}^{e} \geq 0 \\
& \text { Subject to Eq. (18)-(19) and (36)-(47) }
\end{aligned}
$$

In the next section, the numerical example of the stated method is given and analyzed.

\section{Numerical results and sensitivity analysis}

In this section, several numerical examples are designed and solved; furthermore, the numerical results are compared and analyzed. In each example, two scenarios are considered for each parameter of demand and supplier disruptions probability. Two low and high values scenarios are considered for the demand and disruption probability of suppliers; Combination of the addressed scenarios are considered. The first combination refers to the condition in which the demand and the probability of supplier disruptions have the low values. The second combination refers to the condition in which the demand has its low value while the probability of supplier disruptions has its high value. The third combination refers to the condition in which the demand has its high value and the probability of supplier disruptions has its low value. The fourth combination refers to the condition in which the demand and the probability of supplier disruptions have the high values. Each numerical example is solved considering the four aforementioned scenarios together with the extensive SP approach. In fact each numerical examples is solved in five cases. In the first case, each numerical example is solved considering the first combination and the values of the objective functions are obtained. Solving the numerical example and obtaining the solutions, independent variables of other combinations are specified. The obtained independent variables from this solution are considered as constant values and are given to the numerical example; then, the numerical example is solved considering the second combination, the third combination and fourth combination, separately; the values of the objective functions are obtained for each case. Finally, the average of the results is computed. For the second, third, and fourth cases, the given process is repeated considering the second, third, and fourth combinations as the core. Finally, the fifth case refers to the simultaneous solution of all of the four combinations in an integrated model using baseline scenario modeling (i.e. extensive programming).

It is noted that the CPLEX Optimization solver is used to solve these examples. A few numerical problems have been designed that the first example was designed as a basic example; other examples are generated by changing the values of some parameters. In all given examples, values of the first choice of aspirations are considered based on the optimal values of the single function, and the second and third choices for aspirations are considered with $10 \%$ and $20 \%$ variation, respectively, as compared to the optimal value (increase for minimization and decrease for maximization functions). The maximum negative and positive deviations of each choice are also determined by experts. In the basic example, $w_{i}$ and $w w_{k}$ are assumed to be in the interval $[10,50]$, which can be obtained using the well-known AHP or TOPSIS methods [26]. $C_{i j t}$ and $C C_{k j t}$ as capacities of suppliers are are assumed to be in the interval [80, 200]. $P_{i j t}$ get values in the interval $[100,50]$ and $p p_{k j t}$ in the interval $[20,50]$. Values of $a_{i j}$ and $a a_{k j}$ are assumed to be in the interval $[20,50] . T_{j}$ and $Q_{j}$ for all products can get values in the interval $[0.1,0.3]$. Additionally, values of $q q_{k j}, q_{i j}, t_{i j}$, and $t t_{k j}$ have a small amount in the range of $[0,0.1]$. Weights of objective functions for the basic problem are assumed to be identical, i.e. $f_{1}=f_{2}=f_{3}=f_{4}=f_{5}=0.2$. Table 5 gives the exact values of demand and the probability of supplier disruption with regard to the scenarios. 
Table 5. Demand and supplier's disruption values in example 1 (basic example)

\begin{tabular}{|c|c|c|c|c|c|c|c|c|}
\hline \multicolumn{9}{|c|}{ Demand values } \\
\hline$D_{j t}{ }^{1}$ & $t=1$ & $t=2$ & $t=3$ & & $\mathrm{D}_{\mathrm{jt}}^{2}$ & $\mathrm{t}=1$ & $\mathrm{t}=2$ & $\mathrm{t}=3$ \\
\hline$j=1$ & 150 & 100 & 158 & & $j=1$ & 250 & 200 & 350 \\
\hline $\mathrm{j}=2$ & 100 & 80 & 70 & & $\mathrm{j}=2$ & 450 & 500 & 400 \\
\hline \multicolumn{9}{|c|}{ Supplier disruption probability } \\
\hline & & & $\mathrm{K}=1$ & $\mathrm{~K}=2$ & $K=3$ & $\mathrm{k}=4$ & & \\
\hline & & $R_{k}^{1}$ & 0.17 & 0.20 & 0.10 & 0.05 & & \\
\hline & & $R_{k}^{2}$ & 0.30 & 0.38 & 0.25 & 0.35 & & \\
\hline
\end{tabular}

In the second example, the values of supplier disruption probabilities are varied as in Table 6, and the rest of the parameters are in accordance with Example1.

Table 6. Supplier disruption probabilities in example 2

\begin{tabular}{ccccc}
\hline & $\mathrm{k}=1$ & $\mathrm{~K}=2$ & $\mathrm{k}=3$ & $\mathrm{k}=4$ \\
\hline$R_{k}^{1}$ & 0.13 & 0.09 & 0.12 & 0.15 \\
\hline$R_{k}^{2}$ & 0.28 & 0.25 & 0.20 & 0.45 \\
\hline
\end{tabular}

In the third example, $a_{i j}$ and $a a_{k j}$ vary in the interval $[70,100] ; w_{i}$ and $w w_{k}$ vary in the interval $[60,90]$. The rest of the parameters are as in Example 1.

In the fourth numerical example, different values for the demand are considered in accordance with Table 7.
Table 7. Demand values in accordance with scenario example 4

\begin{tabular}{llllllll}
\hline \multicolumn{7}{c}{ Demand values } \\
\hline $\mathrm{D}_{\mathrm{jt}}{ }^{1}$ & $\mathrm{t}=1$ & $\mathrm{t}=2$ & $\mathrm{t}=3$ \\
$\mathrm{j}=1$ & 250 & 100 & 230 \\
$\mathrm{j}=2$ & 110 & 80 & 70
\end{tabular}$\quad$\begin{tabular}{llll}
$\mathrm{D}_{\mathrm{jt}}{ }^{2}$ & $\mathrm{t}=1$ & $\mathrm{t}=2$ & $\mathrm{t}=3$ \\
\cline { 2 - 6 } $\mathrm{j}=1$ & 920 & 630 & 350 \\
\hline $\mathrm{j}=2$ & 240 & 75 & 190 \\
\hline
\end{tabular}

In the fifth example, $q q_{k j}$, $q_{i j}, t_{i j}$, and $t t_{k j}$ get values in the interval [0.1, 0.25]; $T_{j}$ and $Q_{j}$ for all products get values in the interval $[0.2,0.5]$. Other parameters are as in Example 1.

In the sixth example, $p_{i j t}$ gets values in the interval $[100,300]$ and $p p_{k j t}$ in the interval $[60,150]$. The rest of the parameters are as in Example 1.

In the seventh example, $a a_{k j}$ and $c c_{k j t}$ get values in the intervals $[110,150]$ and $[250,400]$, respectively. The rest of the parameters are as in Example 1.

In the eighth to fourteenth examples, the values of parameters from Examples (1) to (6) are repeated in turn with the difference that the weights of the objective functions in the main objective function is the sequel discusses the exploration and analysis of the values of objective functions in the examples. In the extensive SP (simultaneous solving of the combinations) using the scenario-based model, the probability of a combination of scenarios is considered equal to 0.25 (i. e. $\rho^{1}=\rho^{2}=\rho^{3}=\rho^{4}=$ $0.25)$.

Table 8 gives the results of objective functions for each numerical examples.

Table 8. Objective function values of numerical examples 1-14 for different cases

\begin{tabular}{cccccc}
\hline NO & $\begin{array}{l}\text { First case } \\
\text { (first } \\
\text { combination } \\
\text { mode) }\end{array}$ & $\begin{array}{l}\text { Second case } \\
\text { (second } \\
\text { combination } \\
\text { mode) }\end{array}$ & $\begin{array}{l}\text { Third case } \\
\text { (third } \\
\text { combination } \\
\text { mode) }\end{array}$ & $\begin{array}{l}\text { Fourth case } \\
\text { (fourth } \\
\text { combination } \\
\text { mode) }\end{array}$ & $\begin{array}{l}\text { Fifth case (based } \\
\text { on the extensive } \\
\text { stochastic } \\
\text { programming } \\
\text { model) }\end{array}$ \\
\hline 1 & 0.67 & 0.67 & 0.73 & 0.72 & 0.82 \\
\hline 2 & 0.52 & 0.63 & 0.56 & 0.43 & 0.89 \\
\hline 3 & 0.56 & 0.56 & 0.58 & 0.62 & 0.76 \\
\hline 4 & 0.51 & 0.43 & 0.48 & 0.41 & 0.71 \\
\hline 5 & 0.68 & 0.66 & 0.64 & 0.66 & 0.92 \\
\hline 6 & 0.56 & 0.64 & 0.52 & 0.74 & 0.89 \\
\hline 7 & 0.56 & 0.52 & 0.58 & 0.50 & 0.88 \\
\hline 8 & 0.51 & 0.56 & 0.52 & 0.50 & 0.77 \\
\hline 9 & 0.64 & 0.57 & 0.42 & 0.43 & 0.78 \\
\hline 10 & 0.62 & 0.79 & 0.71 & 0.71 & 0.97 \\
\hline 11 & 0.60 & 0.62 & 0.62 & 0.60 & 0.91 \\
\hline 12 & 0.62 & 0.58 & 0.55 & 0.64 & 0.85 \\
\hline 13 & 0.49 & 0.51 & 0.47 & 0.48 & 0.72 \\
\hline 14 & 0.51 & 0.66 & 0.45 & 0.56 & 0.77 \\
\hline Mean & 0.53 & 0.60 & 0.56 & 0.57 & 0.83 \\
\hline
\end{tabular}


With regards to the values of objective functions in all examples and the average of the results of all examples, it is clear that the value of the obtained general objective function through an extensive SP method is significantly different from the average value of the individual solutions of each combination in the first four cases. In all examples, it is clear that if the model is solved with the values of each scenario individually using a definitive model, the value of the objective function is less than the solution of the model rather than the extensive SP method. This difference signifies the importance and positive impact of the extensive SP method. In fact, under the condition that all real-world conditions are identified (such as economic situation, internal and external security, fluctuations in currency market, and sudden natural disasters) and all possible scenarios for demand and disruption probability values can be predicted, the costs of imposed disruption to a supply chain can be minimized through using the extensive SP method.

Additionally, the uncertain mode of supplier disruption probability brings the model closer to the real-world model. The simultaneous combination of the uncertain state of the demand parameter and the possibility of supplier disruption matches the model entirely with the real-world situations.

\section{Conclusions and further research ideas}

In this paper, supplier quota allocation problem based on five objective functions including minimizing total transaction costs, total purchasing costs, total percentages of late delivered products, total percentages of returned goods, and maximizing total evaluation scores of suppliers was studied. A definite model and an extensive scenario-based SP model of the problem were presented. We used fuzzy multichoice goal programming approach to solve the multi-objective problem. Due to the linearity of the model, CPLEX Optimization solver was used; then, a few numerical examples were designed and solved using the single solution method for each combination and the extensive SP method. Finally the obtained results were compared and analyzed. Although there are many deterministic models with thousands of variables and constraints, the results of these models are not accepted by managers due to not considering real world uncertainties. A scenariobased stochastic programming (SP) method is able to consider different scenarios for uncertain parameters, which have significant effects in supply chain operation. In this paper, the parameters of customer demand and supplier disruption probabilities were considered to be uncertain. Combination of different scenarios were considered in this regard. These results are quite clear in the numerical examples. Having several opposite objective functions in the basic model, the multi-choice fuzzy goal programming method was applied in order to make the results closer to the real-world situations.

As further researches in this area, it is possible to use multi-objective meta-heuristic algorithms and multicriteria decision-making methods for selecting suppliers. This can also be achieved through quantifying other benefits of a supply chain and taking into account these benefits in the objective function for a win-win position. Other extensions can be considering various types of supply risks in the model.

\section{References}

[1] Mavi, R.K., Goh, M., Mavi, N. K.: Supplier selection with Shannon entropy and fuzzy TOPSIS in the context of supply chain risk management, Procedia - Social and Behavioral Sciences, 235 (2016), 216-225.

[2] Gómez, J.C.O., Duque, D.F.M., Rivera, L., García-Alcaraz, J.L.: Decision Support System for Operational Risk Management in Supply Chain with 3PL Providers, In Current Trends on Knowledge-Based Systems. Springer International Publishing, (2017), 205-222.

[3] Zhu, W., Ng, S.C., Wang, Z., Zhao, X.: The role of outsourcing management process in improving the effectiveness of logistics outsourcing, International Journal of Production Economics, 188 (2017), 29-40.

[4] Hsiao, H., Kemp, R.G.M., Van der Vorst, J.G.A.J., Omta, S.O.: A classification of logistic outsourcing levels and their impact on service performance: Evidence from the food processing industry, International journal of production economics, 124 (2010) 1, 75-86.

[5] Ware, N.R., Singh, S.P., Banwet, D.K.: A mixedinteger non-linear program to model dynamic supplier selection problem, Expert Systems with Applications, 41 (2014) 2, 671-678.

[6] Dani, S., Deep, A.: Fragile food supply chains Reacting to risks, International Journal of Logistics Research and Applications, 13 (2010) 5, 395-410.

[7] Karpak, B., Kumcu, E., Kasuganti, R.R.: Purchasing materials in the supply chain: managing a multi-objective task, European 
Journal of Purchasing and Supply Management, 7 (2001) 3, 209-216.

[8] Amid, A., Ghodsypour, S.H., O'Brien, C.: Fuzzy multi objective linear model for supplier selection in a supply chain, International Journal of production economics, 104 (2006) 2, 394407.

[9] Lee, Sh.D., Chang, W.T.: On solving the discrete location problems when the facilities are prone to failure, Applied Mathematical Modelling, 31 (2007) 5, 817-831.

[10] Razmi, J., Maghool, E.: Multi -item supplier selection and lot-sizing planning under multiple price discounts using augmented e-constraint and Tchebycheff method, The International Journal of Advanced Manufacturing Technologhy, 49 (2010) 1-4, 379-392.

[11] Li, L., Zabinsky, Z.B.: Incorporating uncertainty into a supplier selection problem, International Journal of Production Economics, 134 (2011) 2,344-356.

[12] Mafakheri, F., Breton, M., Ghoniem, A.: selection-order allocation: a two-stage multiple criteria dynamic programming approach, International Journal of Production Economics, 132 (2011) 1, 52-57.

[13] Ozkok, B.A., Tiryaki, F.: A compensatory fuzzy approach to multi-objective linear supplier selection problem with multiple-item, Expert Systems with Applications, 38 (2011) 9, 1136311368.

[14] Kamali, A., Ghomi, S.F., Jolai, F.: A multiobjective quantity discount and joint optimization model for coordination of a singlebuyer multivendor supply chain, Computers and Mathematics with Applications, 62 (2011) 8, 3251-3269.

[15] Mendoza, A., Ventura, J.A.: Analytical models for supplier selection and order quantity allocation, Applied Mathematical Modelling, 36 (2012) 8, 3826-3835.

[16] Sepúlveda, J.M., Ivan S.D.: Automated Reasoning for Supplier Performance Appraisal in Supply Chains, Procedia Computer Science, 31 (2014), 966-975.
[17] Maden, W., Eglese, R., Black, D.: Vehicle routing and scheduling with time-varying data: A case study, Journal of the Operational Research Society, 61 (2016) 3, 515-522.

[18] Pellegrino, R., Costantino, N., Tauro, D.: Supply Chain Finance: A supply chain-oriented perspective to mitigate commodity risk and pricing volatility, Journal of Purchasing and Supply Management, (2018).

[19] Hsieh, C.C., Chiu, C.C.: Value of on-site rework in a coordinated two-stage supply chain with supply imperfection, Computers and Industrial Engineering, 119 (2018), 262-272.

[20] Zair, F., Sefiani, N., Fourka, M.: Advanced optimization model of resource allocation in B2C chain, Engineering Review, 38 (2018) 3, 328-337.

[21] Heckmann, I., Comes, T., Nickel, S.: A Critical Review on Supply Chain Risk Definition, Measure and Modeling, Omega, 52 (2015), 119132.

[22] Mousazadeh, M., Torabi, S.A., Pishvaee, M.S.: Green and reverse logistics management under fuzziness, In Supply Chain Management under Fuzziness, Springer, Berlin, Heidelberg, 313 (2014), 607-637.

[23] Giri, B.C., Sarker, B.R.: Improving performance by coordinating a supply chain with third party logistics outsourcing under production disruption, Computers and Industrial Engineering, 103 (2017), 168-177.

[24] Seifbarghy, M., Esfandiari, N.: Modeling and solving a multi-objective supplier quota allocation problem considering transaction costs, Journal of Intelligent Manufacturing, 24 (2013) 1, 201-209.

[25] Bankian-Tabrizi, B., Shohanaghi, K., Jobalameli, M. S.: Fuzzy multi-choice goal programming, Applied MathematicalModelling, 36 (2012) 4, 14151420.

[26] Kubat, C., Yuce, B.: A hybrid intelligent approach for supplychain management system, Journal of Intelligent Manufacturin, 23 (2012) 4, 1237-1244. 